DOI: 10.14451/1.185.32

\title{
СОВРЕМЕННОЕ СОСТОЯНИЕ КРЕДИТНО-ФИНАНСОВОЙ СФЕРЫ РФ
}

\author{
(c) 2020 Левченко Лариса Владимировна \\ кандидат экономических наук, доцент \\ Самарский государственный экономический университет, Россия, Самара \\ E-mail: lvls@mail.ru \\ (c) 2020 Осина Дарья Сергеевна \\ магистрант 2 курса кафедры экономической теории \\ Самарский государственный экономический университет, Россия, Самара
}

В данной статье рассмотрена структура отечественного банковского сектора, проанализированы ключевые тенденции, характеризующие его волатильность, выделены основные факторы его трансформации, а также рассмотрено влияние санкционного механизма на устойчивость национальных кредитно-финансовых институтов.

Ключевые слова: банковская система, депозиты, кризис, облигационная задолженность, операционная прибыль, процентная ставка, финансовый актив.

Характеризуя современное состояние кредитно-финансовой сферы РФ, следует отметить, что начиная с 2008 года ситуация в российской экономике начала существенно ухудшаться. Динамика и структура выдаваемых кредитных продуктов напрямую зависела от внешних и внутренних факторов. Наибольшее влияние на темпы экономического роста в целом и динамику банковского кредитования в стоимостном объеме оказали высокая волатильность цен на нефть и сопутствующая безработица в наиболее зависимых от углеводородов отраслях. На рисунке 1 отражена информация о регистрации и лицензировании кредитных организаций РФ, которые действуют по состоянию на январь 2020 года.

Как видно из рисунка 1 большая часть организаций, способная осуществлять операции кредитования являются банковскими структурами. По данным сайта ЦБ РФ по состоянию на январь 2020 года число зарегистрированных кредитных учреждений достигло 561 финансовых институтов. Порядка 469 кредитных организаций обладают возможностью и правом осуществлять привлечение средств в депозиты, 151 организация имеет право осуществлять операции по торговле с драгоценными металлами. Особенность банковской системы РФ состоит в том, что на ее территории действует множество коммерческих банков, однако филиальная сеть наиболее развита лишь у части из них. Например, у ПАО «Сбербанк» насчитывается 10 территориальных банков, 92 филиала в виде головных отделений (так называемые ГОСБ) и порядка 63 филиалов за рубежом в виде иностранных представительств и филиалов [1]. На рисунке 2 отра-

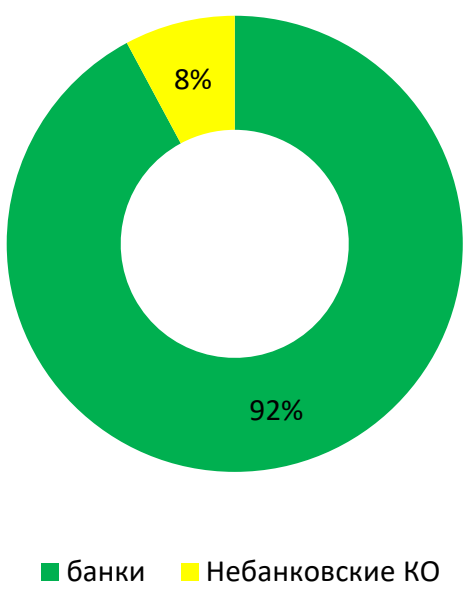

Puc. 1. Кредитные организации, имеющие право осуществлять банковские операции на территории РФ Источник: Официальный сайт Центрального банка Российской Федерации, URL: https://www.cbr.ru/finmarket/inside/inside_detect/table/ 
жена структура официально зарегистрированных и действующих кредитных организаций за исследуемый нами период (2015-2018 гг.)

Структура финансовых институтов испытала существенное сокращение с 833 до 562 кредитных учреждений, обладающих соответствующей лицензией по открытию и сопровождению депозитов. Выявленный спад по большей части обусловлен негативным воздействием экономической рецессии 2014-2015 годов и, как следствием, использованием Центральным Банком РФ своего функционала в плане «чистки рядов» банковских структур [5].

Следует сказать, что, несмотря на отрицательные последствия международного кризиса для экономики РФ и в частности ее банковского сектора открылись новые пути получения операционной прибыли. Мы в данном случае говорим о развитии удаленных каналов обслуживания. Так, исходя из проведенной оценки международной компанией Deloitte Digital, отечественная экономика смогла встать в число лидеров по развитию операций с цифровыми финансовыми активами в европейском, ближневосточном и африканском регионах.

С 2008 по 2019 годы происходил рост количества операций с использованием цифровых финансовых активов, увеличения числа открываемых счетов посредством удаленных каналов обслуживания. Причем наибольшая доля открытия и использования подобных счетов относится к физическим клиентам отечественных банков. На рисунке 3 отражены наиболее часто используемые финансовые цифровые услуги, по состоянию на 2019 год (в \% от общего числа операций).

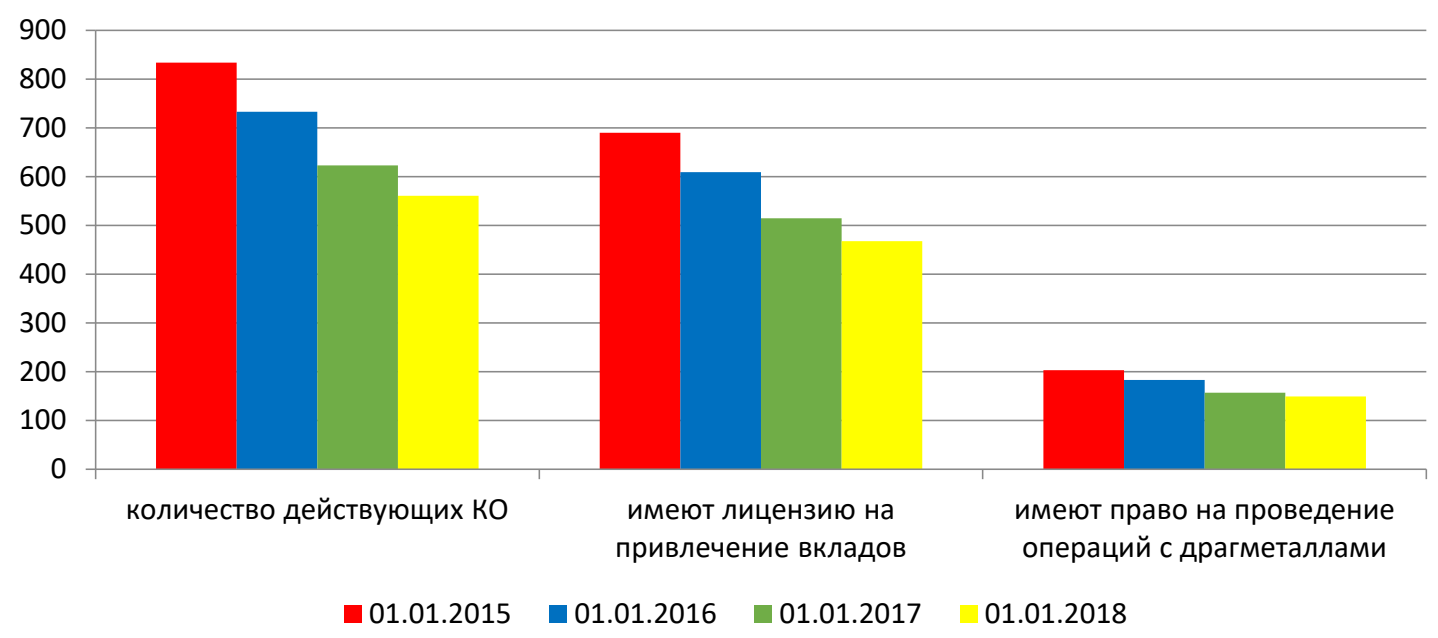

Puc. 2. Количество действующих кредитных учреждений

Источник: Официальный сайт Центрального банка РФ, URL: https://www.cbr.ru/finmarket/inside/inside_detect/table/

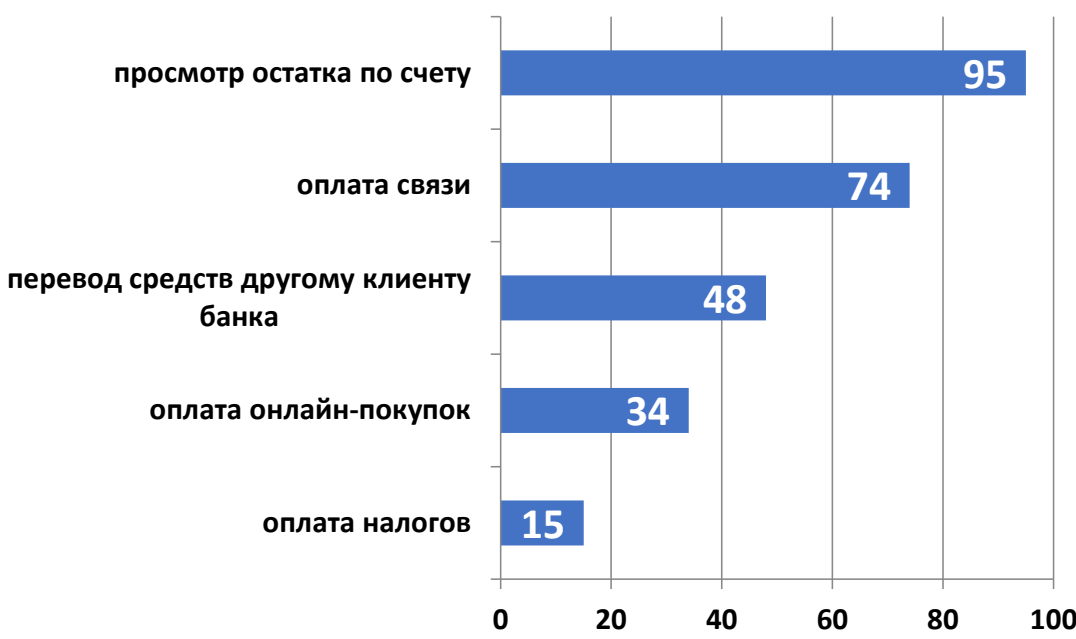

Puc. 3. Базовые элементы банковской системы РФ

Источник: Официальный сайт Центрального банка РФ, URL: https://www.cbr.ru/finmarket/inside/inside_detect/table/ 
Следует указать, что порядка 95\% от количества активных пользователей, использующих каналы дистанционного банковского обслуживания используют функционал таких систем для анализа остатка на расчетном счете и остатка планируемой к погашению ссуды. Самая меньшая доля осуществляемых процедур - операции с торговлей и безмаржинальным обменом валютой (подобных сделок порядка 15-17\%), однако доля подобных операций в 2019 году по сравнению с 2017 годом увеличилась примерно на 11\% [3].

В настоящее время наблюдается тенденция роста числа совершаемых операций с использованием онлайн-сервисов. В таблице 1 указан рейтинг (информация согласно сайту ЦБ РФ) сайтов ведущих банков России по функциональности и эффективности использования механизмов ДБО.

Большая часть технологий приобретается под лицензией за рубежом. Хотя, существуют и очень перспективные отечественные разработки от Яндекса - голосовой помощник «АЛИСА» и от Mail.ru - «Маруся».

Ранее, наиболее популярным кредитным продуктов в розничном сегменте банковского бизнеса в России являлись банковские карты. Однако рост ставки рефинансирования и ее регулярный пересмотр повлекли рост ставок по действующим и вновь заключаемым кредитным договорам. Это сказалось на сокращении использования данного типа банковского продукта

Также, немаловажным аспектом слабого развития онлайн-банкинга в отечественной эконо- мике является слабая законодательная база и поддержка проводимых операций. Определенные сложности банки испытывают с организациями, в рамках взаимодействия в кредитном процессе, не относящихся к банковскому бизнесу и выпадающих из сферы регулирования, регуляторов банковского рынка.

Можно с определенной степенью говорить о воздействии на работу цифрового банкинга самих интернет-провайдеров [2]. Поскольку от качества работы последних зависит стабильность работы банков, скорость и надежность совершаемых ими операций и деловая репутация кредитного учреждения в целом.

Следует указать на существование ряда альтернативным подходам к поиску ресурсов для финансирования национальной экономики [10]. Прежде всего, стоит обратить внимание на финансовые институты Китая и Индии, способные оказать поддержку и компенсировать утраченные источники фондирования. Следует сказать, что поддержку национальному банковскому сектору способны предоставить правительственные фонды, сформированные в период до разворачивания активных фаз кризиса.

В периоды активных фаз экономического кризиса меры правительственной поддержки позволили выделить порядка 860 млрд. руб. ключевым системообразующим банкам РФ в целях понижения процентных ставок, росту депозитов [8].

Следуя направлению глобализации национального банковского сектора, Россия ежегодно теряет десятков банков в год. Причины ухода банков с рынка разные: от невозможности кон-

Таблица 1. Базовые элементы банковской системы РФ

\begin{tabular}{|c|c|c|c|}
\hline Наименование банка & $\begin{array}{c}\text { Общая оценка } \\
\text { эффективности }\end{array}$ & $\begin{array}{c}\text { Оценка функциональ- } \\
\text { ных возможностей }\end{array}$ & $\begin{array}{c}\text { Оценка удобства } \\
\text { пользования }\end{array}$ \\
\hline Тинькофф Банк & 77,4 & 8,2 & 3,9 \\
\hline Промсвязьбанк & 73,5 & 7,9 & 3,7 \\
\hline Альфа-Банк & 66,3 & 7,2 & 3,4 \\
\hline ВТБ & 65,5 & 6,6 & 3,6 \\
\hline Сбербанк & 64,3 & 6,1 & 3,7 \\
\hline Банк УралСиб & 64 & 6,3 & 3,6 \\
\hline Почта Банк & 63 & 7,2 & 3,1 \\
\hline Райффайзенбанк & 62,5 & 6,0 & 3,6 \\
\hline Совкомбанк & 61,8 & 6,8 & 3,2 \\
\hline Банк Открытие & 57,6 & 6,0 & 3,2 \\
\hline
\end{tabular}

Источник: Официальный сайт Центрального банка Российской Федерации, URL: https://www.cbr.ru/finmarket/inside/inside detect/table/ 
курировать с ТНБ и национальными игроками, до лишения лицензии ЦБ РФ [4].

Несмотря на то, что в настоящее время, благодаря разнообразным правительственным мерам, национальная банковская система обладает возможностью к сопротивлению вводимых и поддерживаемых санкций, проблемы с финансированием и получением доступа к интернациональным кредитам сохраняются и ситуация, исходя из последних событий, имеет место ухудшаться. В складывающейся парадигме институтам банковского сектора необходимо проводить переориентацию на внутренний рынок - поиск внутренних клиентов и активное участие в повышение доходности их деятельности в целях будущего наращивания качественного высокодоходного портфеля [9].

Для отдельных российских банков и корпораций с 31.07.2015 были введены новые ограничения в части привлечения финансовых ресурсов: были установлены запреты на предоставление заемных средств на период свыше одного месяца для следующих банков, имеющих в уставном капитале акции участника-государство: ПАО Сбербанк, ПАО ВТБ, АО Газпромбанк, Россельхозбанк, ряда компаний отрасли ТЭК: Роснефть, Газпром нефть, Транснефть, а также предприятий военно-промышленного комплекса (Уралвагонзавод, ОАК, Оборонпром).

В 2015 году объем долга кредитных организаций, осуществляющих финансовую деятельность на международном рынке составила 182 млрд. долл., а суммарный размер погашения кредиторской задолженности и займов составил порядка 60 млрд. долл. [6]. Величина предоставленных кредитов банковскому сектору России от ЦБ РФ практически идентичная размеру зарубежных долговых обязательств финансовых организаций (на середину 2017 года он составляла порядка 10\%). До конца 2020 года Сбербанку необходимо погасить облигационную задолженность на сумму 5,57млрд. долл., ВТБ -24 млрд. долл. Россельхозбанку - 10,3 млрд. долл., Газпромбанку - 14,2 млрд. долл., Внешэкономбанку - 9,89 млрд. долл. [7].

Исходя из сложившейся практики регулярно вводимых санкций со стороны США и лояльных к ним стран, в РФ в конце 2018 года происходило разрабатывание плана действий совместно с Министерством финансов для спасения национальной финансовой системы.
В начале 2018 года в верхнюю палату Конгресса США был внесен законопроект, направленный на заморозку активов российских юридических лиц, отрезание доступа к американской финансовой системе, а также осуществление операций блокирования сделок с американскими резидентами.

Предполагалось введение санкций в отношении таких российских банков: Сбербанк, ВТБ, Газпромбанк, Внешэкономбанк, Россельхозбанк. Интересен факт внедрения санкций в отношении банков, в которых высока доля государственного участия. В отношении же транснациональных банков (далее - ТНБ), работающих на территории России, санкции оказывают минимальное влияние, поскольку терять прибыль и клиентов западные финансовые структуры не намерены.

Разумеется, на волатильность банковского кредитования влияет курс национальной валюты. Череда санкций и падение цен на нефть стали причиной роста нестабильности финансового, валютного рынка. Вследствие ослабления курса рубля российский банковский сектор столкнулся с риском снижения ликвидности.

Череда вводимых санкций планомерно ухудшает снижение рейтинга нашей страны и национальных финансовых институтов, что негативно сказывается на дальнейшей возможности проводить с их стороны операции по внешнему фондированию.

Так, в декабре 2014 г. международные рейтинговые агентства (Fitch, Moody's и S\&P) произвели понижение суверенного рейтинга РФ до BBB-. Снижение рейтинга страны одновременно вызвало снижение рейтинга институтов кредитного сектора. Большинство банков, попавших под снижение рейтинга стали обладателями негативный прогноза по дальнейшему развитию. Вышеуказанные обстоятельства стали причинами снижения уровень доверия к банкам в РФ, что отразилось на их возможности привлекать зарубежные инвестиции, банковский капитал и крупных частных вкладчиков.

Современная тенденция на российском банковском рынке отражает ухудшение финансового состояния, как кредиторов, так и заемщиков. Причем сложившаяся конъюнктура рынка в ближайшем будущем не претерпит каких-либо изменений. Это может говорить о дальнейшем падении привлекательности российского биз- 
неса, как для внутренних, так и для внешних кредиторов [11]. Вследствие описанных выше процессов будет происходить дальнейшее увеличение рисков на каждого заемщика, рост размера резерва на восполнение потерь по ссудам, ухудшению кредитного портфеля и снижению такого необходимого для экономики направления кредитования, как финансирование инвестиционных проектов.

\section{Библиографический список}

1. Вайпан В.А., Егорова М.А. Правовое регулирование экономических отношений в современных условиях развития цифровой экономики. Монография. Изд-во: Юстицинформ, Москва. 2019. - 376 С.

2. Филиппов А.Е. Отдельные правовые аспекты регулирования оборота цифровых активов в России и за рубежом // Арбитражные споры. 2018. № 4. С. 23-28.

3. Курманова Д.А. Финансовые технологии на розничном рынке банковских услуг // Вестник УГНТУ. Наука, образование, экономика. Серия экономика. № 1 (27), 2019. С. 60-67.

4. План мероприятий («дорожная карта») по реализации основных направлений развития финансового рынка Российской Федерации на период 2019-2021 годов [Электронный ресурс]. Режим доступа: https://www. garant.ru/products/ipo/prime/doc/72117776/\#review.

5. Храпченко Л.. Структурированные продукты в России // Forbes, российское издание. - 2016. - № 7 (28) - с. 100-102.

6. Нетунаев Е.Б. Причины формирования финансовых пузырей и методы борьбы с ними на развивающихся фондовых рынках // Вестник СПбГУ. Менеджмент. 2018. Т.17, № 3. - С. 359-383.

7. Шестакова Е. Чего стоит ожидать российскому бизнесу? Прогноз экономических перемен на 2019 год // Финансовая газета, № 32. 2018. [Электронный ресурс]. - https:// fingazeta.ru, заголовок с экрана

8. Центральный банк РФ. Основные направления развития финансового рынка РФ на период 2016-2018 годов.- С. 40. [Электронный ресурс]: - Режим доступа: https://www.cbr.ru/finmarkets/files/development/ onrfr_2016-18.pdf

9. Михайлов А. М. Реализация экономических и институциональных интересов в процессе становления в России постиндустриального общества // Вестн. Самар. фин.-экон. ин-та. - 2011. - № 2.- С. 4.

10. Левченко Л.В. Венчурный капитал и источники его привлечения //Вестник Самарского государственного экономического университета.2012. - № 11 (97)- С.75.

11. Рязанова О.Е. Институт промышленной собственности в инновационной экономике. М. - 2014. - С. 42. 